\title{
Metadata Correction: Mobile Phone Ownership Is Not a Serious Barrier to Participation in Studies: Descriptive Study
}

Emily J Harvey ${ }^{1}$, MA; Leslie F Rubin ${ }^{1,2}$, MS; Sabrina L Smiley ${ }^{1}$, PhD, MPH, MCHES; Yitong Zhou ${ }^{1}$, MS; Hoda Elmasry $^{1}$, MPH; Jennifer L Pearson ${ }^{1,3}$, MPH, PhD

${ }_{1}^{1}$ Truth Initiative, Schroeder Institute for Tobacco Research and Policy Studies, Washington, DC, United States

${ }^{2}$ Department of Psychology, American University, Washington, DC, United States

${ }^{3}$ Department of Health, Behavior, and Society, Bloomberg School of Public Health, Johns Hopkins University, Baltimore, MD, United States

\section{Corresponding Author:}

Emily J Harvey, MA

Truth Initiative

Schroeder Institute for Tobacco Research and Policy Studies

900 G St NW Fourth Floor

Washington, DC, 20001

United States

Phone: 12024545768

Email: eharvey@truthinitiative.org

\section{Related Article:}

Correction of: http://mhealth.jmir.org/2018/2/e21/

(JMIR Mhealth Uhealth 2018;6(4):e10403) doi: 10.2196/10403

In the metadata for "Mobile Phone Ownership Is Not a Serious Barrier to Participation in Studies: Descriptive Study" (JMIR Mhealth Uhealth 2018;6(2):e21), the degrees for Sabrina L Smiley were listed in an incorrect order as "MCHES, MPH, $\mathrm{PhD}$ ". The degrees should have been ordered "PhD, MPH, MCHES".
The corrected article will appear in the online version of the paper on the JMIR website on April 25, 2018, together with the publication of this correction notice. Because this was made after submission to PubMed or Pubmed Central and other full-text repositories, the corrected article also has been re-submitted to those repositories.

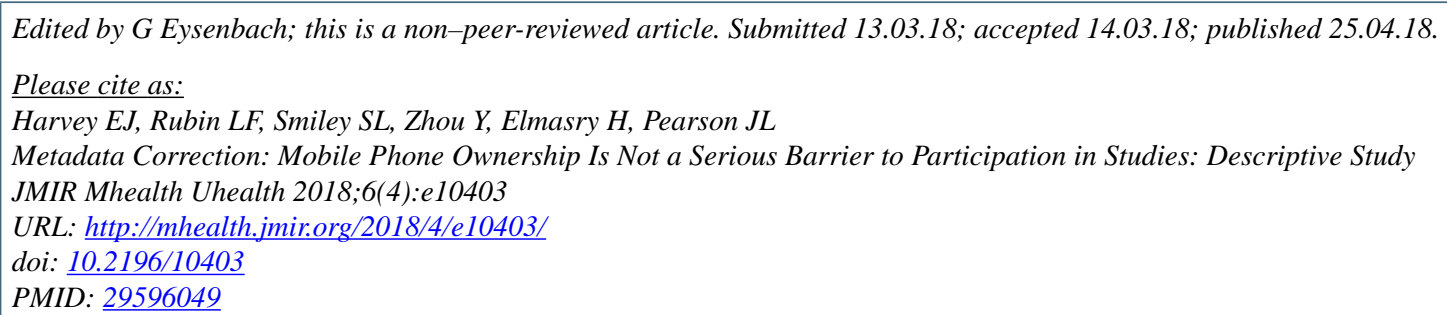

CEmily J Harvey, Leslie F Rubin, Sabrina L Smiley, Yitong Zhou, Hoda Elmasry, Jennifer L Pearson. Originally published in JMIR Mhealth and Uhealth (http://mhealth.jmir.org), 25.04.2018. This is an open-access article distributed under the terms of the Creative Commons Attribution License (https://creativecommons.org/licenses/by/4.0/), which permits unrestricted use, distribution, and reproduction in any medium, provided the original work, first published in JMIR mhealth and uhealth, is properly cited. The complete bibliographic information, a link to the original publication on http://mhealth.jmir.org/, as well as this copyright and license information must be included. 